\title{
Patient Perspectives on Breast Cancer Treatment Plan and Summary Documents in Community Oncology Care
}

\author{
A Pilot Program \\ Victoria S. Blinder, MD, MSc'; Virginia W. Norris, MGC²; Nancy W. Peacock, MD³; Jennifer J. Griggs, MD, MPH ${ }^{4}$; \\ David P. Harrington, $\mathrm{PhD}^{5}$; Anne Moore, MD ${ }^{6}$; Richard L. Theriault, DO, MBA, FACP ${ }^{7}$; Ann H. Partridge, MD, MPH ${ }^{8}$; on behalf \\ of the American Society of Clinical Oncology Breast Cancer Registry Pilot Steering Group
}

BACKGROUND: Although the routine use of treatment plans and summaries (TPSs) has been recommended to improve the quality of cancer care, limited data exist about their impact on quality, including patient satisfaction and coordination of care. METHODS: Patients received TPSs as part of the American Society of Clinical Oncology Breast Cancer Registry (BCR) pilot program of 20 community oncology practices. Participants were surveyed 2 to 4 weeks after receiving a TPS to evaluate their perceptions of the document. Patients who were receiving chemotherapy received the TPS as separate plan and summary documents (at the start and the end of treatment) and could complete 2 surveys. Others received a single integrated TPS. Eligible survey participants had stage 0 through III breast cancer and were enrolled in the BCR. RESULTS: Of 292 consented patients, 174 (60\%) completed at least 1 survey. Of 157 patients who recalled receiving a TPS, 148 (94\%) believed that the documents improved patient-physician communication, and 128 (82\%) believed that they improved communication between physicians; 113 (72\%) said the documents increased their peace of mind, whereas $2(1 \%)$ had less peace of mind. Of 152 patients (97\%) who still had their documents, 147 (97\%) said they were useful, and $94(62 \%)$ had given or planned to give the documents to another physician. All 63 patients who were surveyed after receiving a summary recommended that practices continue to provide TPSs to patients. CONCLUSIONS: Participants in this study expressed high satisfaction with TPSs. Additional research is needed to study the broad-scale implementation of the BCR and to evaluate the impact of routine use of TPSs on the quality of care delivered. Cancer 2013;119:164-72. (C) 2012 American Cancer Society.

KEYWORDS: survivorship, breast cancer, treatment plan, treatment summary, survivorship care plan.

\section{INTRODUCTION}

The oncology workforce is shrinking relative to the increasing number of cancer survivors, and a possible solution is to transition survivors to the care of primary care physicians (PCPs) after an adequate period of surveillance by the oncology practitioner. ${ }^{1,2}$ Because breast cancer survivors represent nearly $25 \%$ of all cancer survivors in the United States, much attention has been focused on this group. ${ }^{3}$ Research has demonstrated that almost half of PCPs feel unprepared to care for cancer survivors, and most believe they receive insufficient information about their patients' cancer diagnoses and treatments. ${ }^{3-5}$ Patients also report that a major limitation in survivorship care is inadequate communication between oncologists and PCPs, and breast cancer survivors have reported feelings of anxiety and abandonment after completing their treatment. ${ }^{6-9}$ Only $41 \%$ of breast cancer patients believe that their PCPs know how to treat symptoms related to cancer or associated therapies. ${ }^{10}$ Communication problems also exist between patients and physicians during the treatment period, when survivors report confusion about the chemotherapy schedule and expected side effects. ${ }^{8,11}$ Integrating survivorship care plans into the practice of oncology has emerged as a possible solution to these problems and has been recommended as an important step in improving the quality of cancer care by several recent reports and organizations, including the American Society of Clinical Oncology (ASCO) and the Institute of Medicine. ${ }^{12-16}$

\footnotetext{
Corresponding author: Victoria S. Blinder, MD, MSc, Department of Epidemiology and Biostatistics, Center for Health Policy and Outcomes, Memorial Sloan-Kettering Cancer Center, 300 East 66th Street, 14th Floor, New York, NY, 10065; Fax: (646) 227-7102; blinderv@mskcc.org

${ }^{1}$ Department of Epidemiology and Biostatistics, Memorial Sloan-Kettering Cancer Center, New York, New York; ${ }^{2}$ American Society of Clinical Oncology, Alexandria, Virginia; ${ }^{3}$ Tennessee Oncology, PLLC, Nashville, Tennessee; ${ }^{4}$ Department of Internal Medicine, Division of Hematology/Oncology, University of Michigan Medical School, Ann Arbor, Michigan; ${ }^{5}$ Department of Biostatistics, Dana-Farber Cancer Institute, Boston, Massachusetts; ${ }^{6}$ Department of Medicine, Weill Cornell Medical College, New York, New York; ${ }^{7}$ Department of Breast Medical Oncology, The University of Texas MD Anderson Cancer Center, Houston, Texas; ${ }^{8}$ Department of Medical Oncology, Dana-Farber Cancer Institute and Brigham and Women's Hospital, Boston, Massachusetts.
}

See editorial on pages 4-6 and related article on pages 158-63, this issue.

We gratefully acknowledge all of the patients and practices who participated in the pilot as well as the Outcome Sciences and American Society of Clinical Oncology staff for their support of this study.

DOI: 10.1002/cncr.27856, Received: January 3, 2012; Revised: May 4, 2012; Accepted: May 17, 2012, Published online November 29, 2012 in Wiley Online Library (wileyonlinelibrary.com) 
In previous research, survivors who had finished treatment reacted favorably to the idea of both treatment and survivorship care plan documents and said that they would have liked to have received such documents as part of their care. ${ }^{6,8,9,11,17}$ In a small, qualitative study, breast cancer survivors reacted favorably to personalized survivorship care plans administered 2 weeks after treatment completion. ${ }^{7}$ In contrast, a recent randomized controlled trial of survivorship care plans administered to Canadian breast cancer survivors who were at least 3 months posttreatment did not demonstrate an associated benefit in terms of quality of life or patient satisfaction. ${ }^{18}$ However, none of the results published to date include patients' perceptions of plans that were incorporated into their care at the time of treatment initiation, when they may be most important in facilitating communication with the treating clinician.

ASCO developed online templates as tools oncologists can use to improve physician-patient and physicianphysician communication. ${ }^{19}$ These 2-page templates are different from many other survivorship care plans, because they exist with 2 distinct parts-a treatment plan and a treatment summary. The Breast Cancer Adjuvant Treatment Plan Template, which is used when the patient starts the adjuvant regimen, includes information about the agents prescribed, anticipated treatment schedule, and possible side effects. It also includes clinical data about the patient, such as date and type of breast surgery, tumor stage and characteristics, and family history. The Treatment Summary Template is used when the patient completes the regimen and includes information from the treatment plan as well as the dates when treatments were completed, cumulative doses of relevant drugs (eg, anthracyclines), toxicities experienced by the patient, and survivorship care recommendations. These templates may be completed, printed, incorporated into the medical record, and shared with the patient and other providers.

Although several treatment plan and summary (TPS) templates have been developed, we know little about patients' reactions to receiving such documents. To address this gap in the literature, we evaluated patient perspectives regarding the integration of TPSs based on the ASCO templates into their clinical care. This study was part of a larger program, the ASCO Breast Cancer Registry (BCR) Pilot Program, which entailed the creation of a registry of patients enrolled through 20 US community oncology practices. Registry data were used to create customized TPSs to be shared with patients. In this report, we describe the perspectives of patients who participated in a research survey as part of the BCR Pilot Program. A separate report documents implementation of the registry and the perspectives of participating oncology practices regarding the $\mathrm{BCR}{ }^{20}$

\section{MATERIALS AND METHODS}

\section{Setting}

Twenty diverse oncology practices from the ASCO membership were selected to participate in the BCR. The recruitment of oncology practices to our study and their training in the use of the registry are described in an accompanying article. ${ }^{20}$ Briefly, practices were selected to optimize diversity in practice size, type of practice (academic vs community), geographic location, patient population (including languages spoken and insurance type), and participation in the ASCO Quality Oncology Practice Initiative.

Each practice appointed a site principal investigator who was responsible for overseeing the patient informedconsent process at that site. The New England Institutional Review Board approved the study on behalf of ASCO and 13 of the participating practices. Seven practices obtained approval from their own institutional review boards.

\section{Study Participants}

Practice staff entered treatment plan and summary data into the BCR for all newly diagnosed patients with stage 0 through III breast cancer who received treatment from a participating oncologist during the pilot. Practices were instructed to offer all patients TPSs and to discuss the documents with patients (Fig. 1). Practice staff determined the structure of these discussions. Patients who were receiving chemotherapy received the TPS as separate plan and summary documents (at the beginning and end of treatment, respectively). Others received a single integrated TPS. After at least 4 months of registry participation by a practice, the practice staff began to consent and enroll participants in the patient survey study. Patients who accepted the TPSs were eligible to participate in the survey study if they read and spoke English and were aged $\geq 18$ years. Each practice was instructed to recruit consecutive patients to the survey study until 10 patients from that practice had completed a survey or the survey period concluded. Patients were surveyed between March 2010 and November 2010.

\section{Data collection}

The survey study started only after practices had become familiar with using the registry and sharing the TPS documents with patients. Participants who received chemotherapy had the opportunity to complete a 


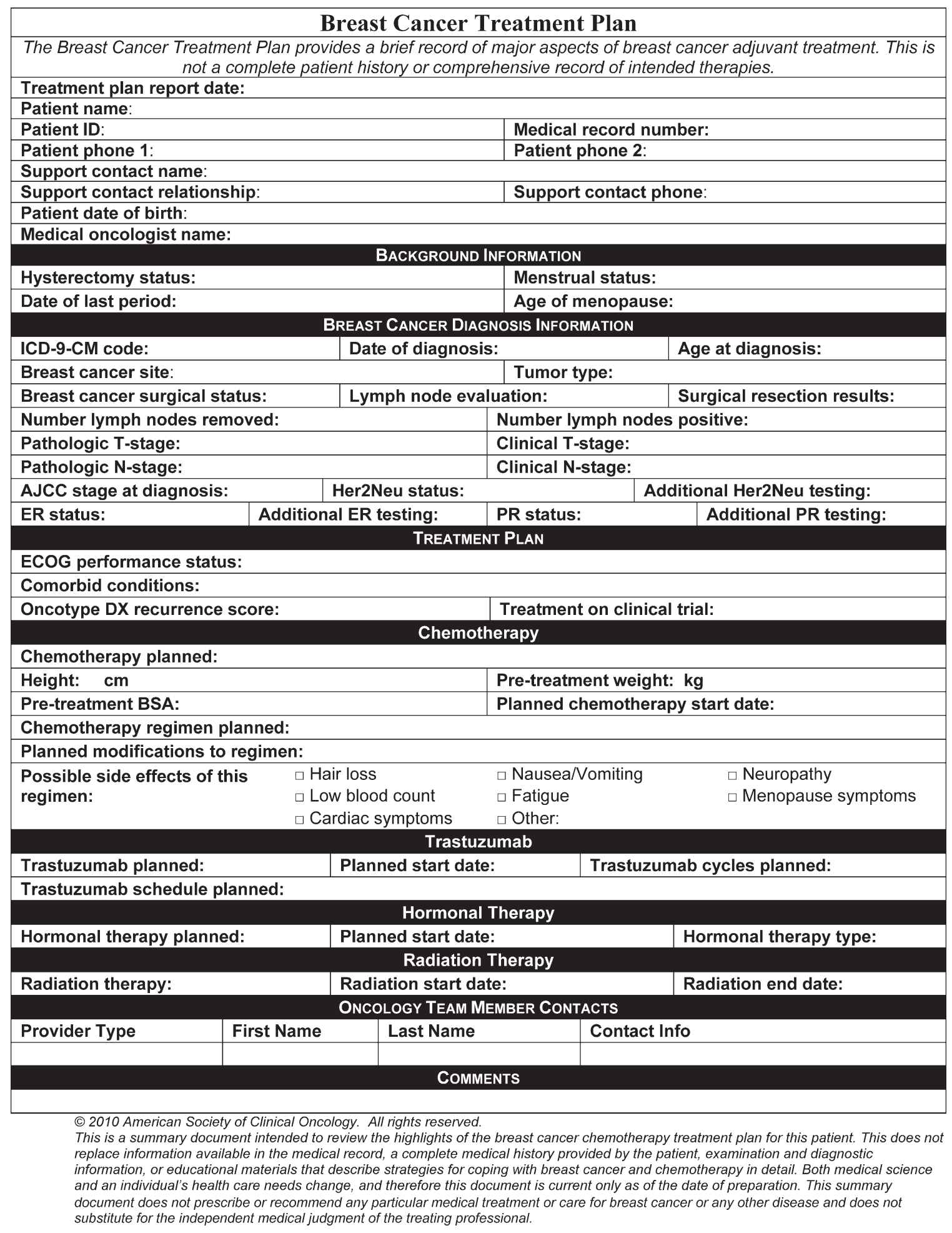

Figure 1. This is a blank American Society of Clinical Oncology breast cancer treatment planning form. ICD-9-CM indicates International Classification of Diseases, Ninth Revision, Clinical Modification; AJCC, American Joint Committee on Cancer; Her2Neu, human epidermal growth factor receptor; ER, estrogen receptor; PR, progesterone receptor; ECOG, Eastern Cooperative Oncology Group; BSA, body surface area. 
telephone survey twice, 2 to 4 weeks after receiving a treatment plan and 2 to 4 weeks after receiving a summary. Although the intent was to obtain 2 surveys from each patient who received chemotherapy, because of time and funding constraints of this pilot study, we allowed patients who were not surveyed after they received a treatment plan to complete a survey after they finished treatment and received a summary. However, all patients who received chemotherapy received both a treatment plan and a treatment summary document, regardless of the number of surveys they completed. Those who did not receive chemotherapy were offered a single survey 2 to 4 weeks after receiving an integrated TPS. The surveys occurred 2 to 4 weeks after the receipt of a document so that participants would have time to process and share the document if they wished to do so. An independent survey vendor, Alan Newman Research (available at: http:// www.anr.com/home.html [Accessed October 12, 2012]), administered the telephone surveys and made up to 10 attempts to contact each consented patient.

\section{Study instruments}

A study steering committee comprised of ASCO volunteers, staff, and expert consultants developed the surveys to assess patient perceptions of the coordination of their care and the quality of communication with their oncologists. The three 15-minute to 20-minute surveys (post-treatment plan, post-treatment summary, and postintegrated TPS) were similar in questions and scope, although some questions differed in the tense used and the name of the document discussed. Participants used a 4-point scale to rate their understanding of the TPS and their treatment, the impact of the TPS on communication with and between clinicians, the usefulness of the TPS and likelihood that they would refer back to it, the amount of information received, and the amount of support provided by the medical oncologist and other health professionals overall during treatment. Participants also indicated whether the TPS gave them greater or less peace of mind or whether it had no impact. In the postsummary survey, participants indicated whether they recommended that their physicians continue providing TPS documents to their patients (yes, no, not sure). Participants could suggest improvements to the TPSs in response to 3 openended questions asking: 1) what, if anything they liked about the documents; 2) what, if anything, they disliked about the documents; and 3) whether they had any suggestions or comments for improving the information in the documents.

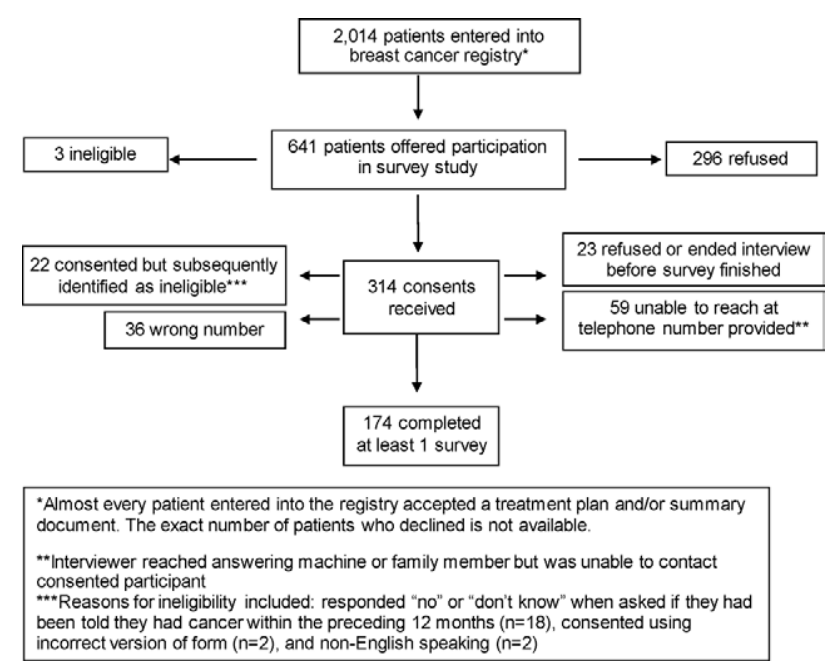

Figure 2. This chart illustrates recruitment flow.

\section{Analysis}

Given the similarities between the treatment plan, summary, and integrated plan/summary documents, and in light of similarities between the corresponding surveys, we conducted a single analysis of the data from all of the surveys. The data set included the responses to 1 survey from each participant regardless of whether the responses were obtained after a treatment plan, summary, or combined document was given to the participant. Only 8 participants completed 2 surveys, and we included only the responses from the second survey.

Because this was a pilot study, most planned analyses were exploratory and descriptive. We analyzed patient satisfaction by asking whether or not participants recommended that practices continue to provide the documents to their patients. Additional related outcomes that were assessed in all surveys included participant perceptions of the documents' impact on their peace of mind, preparation for treatment, communication with physicians, communication between physicians, and clinician support. Verbatim transcripts of answers to the 3 open-ended questions were analyzed by a single investigator (V.S.B.) according to the themes that emerged. Formal qualitative methodology and qualitative research software were not deemed necessary for this straightforward analysis, and they were not used. The themes were summarized, and salient quotations representing each are presented.

\section{RESULTS}

Of 292 eligible, consented participants, 174 (60\%) from 18 different practices completed a survey (Fig. 2). Clinical and demographic characteristics of both the study and 
TABLE 1. Participant Characteristics

\begin{tabular}{|c|c|c|}
\hline \multirow[b]{2}{*}{ Characteristic } & \multicolumn{2}{|c|}{ No. of Participants (\%) } \\
\hline & $\begin{array}{c}\text { Patient Survey } \\
\text { Participants, } \mathrm{n}=174\end{array}$ & $\begin{array}{c}\text { Registry Participants, } \\
n=2014\end{array}$ \\
\hline Age: Median [range] & $58[27-87]$ & 59 [21-95] \\
\hline \multicolumn{3}{|l|}{ Sex } \\
\hline Women & $171(98)$ & 2004 (99) \\
\hline Men & $3(2)$ & $10(1)$ \\
\hline \multicolumn{3}{|l|}{ Race/ethnicity ${ }^{a}$} \\
\hline White, non-Latino & $146(84)$ & $1169(58)$ \\
\hline African-American & $16(9)$ & $205(10)$ \\
\hline Latino & $3(2)$ & $78(4)$ \\
\hline Asian & $2(1)$ & $108(5)$ \\
\hline American Indian or Alaska Native & $2(1)$ & $6(<1)$ \\
\hline Other & $4(2)$ & $18(1)$ \\
\hline Don't know ${ }^{b}$ & $1(1)$ & $89(4)$ \\
\hline Not reported & & $345(17)$ \\
\hline \multicolumn{3}{|l|}{ Disease stage } \\
\hline 0: DCIS & $13(7)$ & $270(13)$ \\
\hline 1 & $68(39)$ & $773(38)$ \\
\hline ॥ & $51(29)$ & $535(26)$ \\
\hline III & $20(11)$ & $192(9)$ \\
\hline $\mathrm{IV}^{\mathrm{b}}$ & $0(0)$ & $10(<1)$ \\
\hline Not sure & $19(11)$ & $234(12)$ \\
\hline Refused to respond ${ }^{b}$ & $3(2)$ & \\
\hline \multicolumn{3}{|c|}{ Treatment received or planned at time of survey ${ }^{c}$} \\
\hline Chemotherapy alone & $86(49)$ & $329(16)$ \\
\hline Endocrine therapy alone & $40(23)$ & $893(44)$ \\
\hline Chemotherapy and endocrine therapy & $10(6)$ & $565(28)$ \\
\hline No chemotherapy or endocrine therapy & $29(17)$ & $227(11)$ \\
\hline Not sure ${ }^{\mathrm{b}}$ & $5(3)$ & \\
\hline Refused to respond ${ }^{b}$ & $4(2)$ & \\
\hline \multicolumn{3}{|l|}{ Education ${ }^{d}$} \\
\hline Did not finish high school & $7(4)$ & \\
\hline High school diploma or GED & $35(20)$ & \\
\hline Some college or 2-y degree & $72(41)$ & \\
\hline Four-y college degree & $23(13)$ & \\
\hline Graduate studies or degree & $35(20)$ & \\
\hline Refused to respond & $2(1)$ & \\
\hline \multicolumn{3}{|l|}{ Annual household income ${ }^{d}$} \\
\hline$<\$ 20,000$ & $18(10)$ & \\
\hline$\$ 20,000-\$ 40,000$ & $27(16)$ & \\
\hline$\$ 40,000-\$ 60,000$ & $28(16)$ & \\
\hline$\geq \$ 60,000$ & $76(43)$ & \\
\hline Don't know/refused to respond & $25(14)$ & \\
\hline
\end{tabular}

Abbreviations: DCIS, ductal carcinoma in situ; GED, General Educational Development.

a One or more race could be selected in the registry (sum of categories, $>2014$ ).

${ }^{\mathrm{b}}$ This information was not an available response in the registry.

${ }^{c}$ Practices reported difficulty consenting patients who did not receive chemotherapy because of practice flow.

${ }^{\mathrm{d}}$ This information was not collected by the registry.

registry samples are summarized in Table 1 . Survey participants were more likely to be white (17\% of registry participants did not have race/ethnicity recorded) and to have received chemotherapy than the registry sample as a whole, but the cancer stage distribution of the 2 groups was similar. Within the survey sample, $66 \%$ did not have a 4 -year college degree, whereas $42 \%$ had an annual household income $<\$ 60,000$. Of 174 participants surveyed, 157 (90\%) said they remembered receiving a TPS, and 152 of those participants (97\%) said they still had the document.

Almost $75 \%$ of participants who remembered receiving a TPS reported that the document gave them greater peace of mind, $24 \%$ said it made no difference, and $1 \%$ said the document gave them less peace of mind (Table 2). Ninety-seven percent of participants who still had their TPS said the document was "useful." Ninety percent of participants said they were likely to refer back 
TABLE 2. Patient Satisfaction and Communication With Physicians

\begin{tabular}{|c|c|c|c|c|c|c|}
\hline \multirow[b]{2}{*}{ Perceptions About Communication } & & \multicolumn{5}{|c|}{ Patient Perceptions: No. of Participants (\%), $\mathrm{n}=157^{\mathrm{a}}$} \\
\hline & & Very Much & Moderately & A Little & Not At All & $\begin{array}{c}\text { Not } \\
\text { Sure/Refused }\end{array}$ \\
\hline \multirow{4}{*}{\multicolumn{2}{|c|}{$\begin{array}{l}\text { The patient understood the document } \\
\text { The document improved communication with physician } \\
\text { The document improved communication between physicians } \\
\text { The document is or will be useful, } \mathrm{n}=152^{\mathrm{b}}\end{array}$}} & $115(73.2)$ & $36(22.9)$ & $3(1.9)$ & $1(0.6)$ & $1(0.6) / 1(0.6)$ \\
\hline & & $90(57.3)$ & $51(32.5)$ & $7(4.4)$ & $2(1.3)$ & $5(3.2) / 2(1.3)$ \\
\hline & & $83(52.9)$ & $40(25.5)$ & $5(3.2)$ & $7(4.4)$ & $20(12.7) / 2(1.3)$ \\
\hline & & $104(68.4)$ & $35(23)$ & $8(5.3)$ & $3(2)$ & $1(1.3) / 0(0)$ \\
\hline \multirow[b]{2}{*}{ Perceptions About Peace of Mind } & \multicolumn{6}{|c|}{ Patient Perceptions: No. of Participants (\%), $n=157^{a}$} \\
\hline & Greater & Diff & ence & Less & Not Sure & Refused \\
\hline \multirow[t]{2}{*}{ Impact of the document on peace of mind } & $113(72)$ & & 4.2) & $2(1.3)$ & $4(2.5)$ & $0(0)$ \\
\hline & \multicolumn{6}{|c|}{ Patient Perceptions: No. of Participants (\%), $\mathrm{n}=157^{\mathrm{a}}$} \\
\hline Perceptions About Future Use of Document & \multicolumn{2}{|c|}{ Very Likely } & $\begin{array}{l}\text { Somewhat } \\
\text { Likely }\end{array}$ & $\begin{array}{c}\text { Not At } \\
\text { All Likely }\end{array}$ & Not Sure & Refused \\
\hline The patient is likely to refer back to the document & \multicolumn{2}{|c|}{$88(56)$} & $54(34.4)$ & $13(8.3)$ & $1(0.6)$ & $1(0.6)$ \\
\hline
\end{tabular}

to the document as they received treatment or in the future. All 63 participants who answered a postsummary survey recommended that their practice continue to provide TPSs to patients (this question was only asked in the postsummary survey).

Ninety-four percent of all participants who remembered receiving a TPS reported that the document had improved or would improve communication between themselves and their physicians (Table 2). Eighty-two percent said they thought the document had improved or would improve communication between their different health care providers. Sixty-two percent said they had given or would give their TPS to another physician, such as their PCP (data not shown), and $97 \%$ of those participants thought it would be useful to the physician. Only $3 \%$ said they thought the document would be not at all useful.

Ninety-eight percent of participants said they understood their TPS (Table 2). Of 136 participants who received or planned to receive systemic therapy (chemotherapy, endocrine therapy, or both), $96 \%$ said they were prepared for what to expect from their treatment (Table 3). Overall, $69 \%$ of all participants said they had received about the right amount of information regarding their cancer and its treatment, whereas $16 \%$ said they received more information than was needed, and 13\% said they received less than was needed (Table 3 ).

Seventy-one percent of participants reported that their oncologists discussed the TPS with them. Only 20\% said they discussed it with someone else in the practice, such as a nurse, and $8 \%$ reported that nobody in the practice discussed the document with them. Eighty-five percent thought the individual who discussed the summary with them did so "very well" (13\% said "moderately well"). Greater than $66 \%$ of participants believed they received about the right amount of support from their medical oncologist and other health professionals, whereas $19 \%$ said they received more support than was needed (Table 3). Only 9\% received less support than was needed. Greater than $75 \%$ of participants indicated that their medical oncologist listened to them "very much," and $18 \%$ said their oncologist listened to them "moderately." Similar proportions said their oncologist answered their questions (87\% said "very much," and $10 \%$ said "moderately").

\section{Participants' Comments in Response to Open-Ended Questions}

Participants were asked to comment on what, if anything, they liked and disliked about the TPSs. They also were 
TABLE 3. Amount of Information and Support: Feeling Prepared for Treatment

\begin{tabular}{|c|c|c|c|c|c|c|c|}
\hline \multirow[b]{2}{*}{ Perceptions About Support } & \multicolumn{7}{|c|}{ Patient Perceptions: No. of Participants (\%), n = 174} \\
\hline & $\begin{array}{l}\text { More Than } \\
\text { Needed }\end{array}$ & $\begin{array}{l}\text { About } \\
\text { Right }\end{array}$ & \multicolumn{2}{|c|}{$\begin{array}{l}\text { A Little Less } \\
\text { Than Needed }\end{array}$} & $\begin{array}{l}\text { A Lot Less } \\
\text { Than Needed }\end{array}$ & Not Sure & Refused \\
\hline Support from medical oncologist and other health professionals & $33(19)$ & $121(69.5)$ & & (7.5) & $2(1.1)$ & $4(2.3)$ & $1(0.6)$ \\
\hline \multirow[t]{2}{*}{ Information about cancer and treatment } & $28(16.1)$ & $120(69)$ & & 12.1) & $1(0.6)$ & $4(2.3)$ & $0(0)$ \\
\hline & \multicolumn{7}{|c|}{ Patient Perceptions: No. of Participants (\%), $n=174$} \\
\hline Perceptions About Preparedness for Treatment & Very Much & Mode & rately & A Little & Not At All & Not Sure & Refused \\
\hline Oncologist listened to patient & $137(78.7)$ & 32( & |8.4) & $3(1.7)$ & $0(0)$ & $2(1.1)$ & $0(0)$ \\
\hline Oncologist answered patient's questions & $152(87.4)$ & 18( & 10.3) & $2(1.1)$ & $0(0)$ & $1(0.6)$ & $1(0.6)$ \\
\hline Patient felt prepared for what to expect from treatment, $n=136^{b}$ & $77(56.6)$ & $48(3$ & 35.3) & $6(4.4)$ & $3(2.2)$ & $1(0.7)$ & $1(0.7)$ \\
\hline Patient understood treatment received or planned, $n=136^{b}$ & $89(65.4)$ & $41(3$ & 30.1) & $3(2.2)$ & $0(0)$ & $1(0.7)$ & $2(2.2)$ \\
\hline
\end{tabular}

a This response was "very well" for the last 2 questions in the table.

${ }^{\mathrm{b}}$ In total, 136 patients received systemic therapy.

asked for suggestions on how to improve the documents. Eighty-six percent of participants gave comments about what they liked, including the clarity of the documents, their use in communication with family and clinicians, and an increased sense of empowerment. Participant comments are summarized below, and salient participant quotations are provided after each category.

The document was clear and concise: "It (the document) just condenses everything. When you first hear even the word "cancer," it kind of jumbles everything in your mind. It just condenses everything for me so that it is just easier for me to know what to do..."

Participants used the document to facilitate discussions with family members: "My whole family knows how long it's going to go. It (the document) reduces their anxiety. They know it's going to be long and occur in 4 stages, and they have met the people in each stage. We don't have to pass a lot of information to each other-just support. So they are not asking questions about what is going to happen now, just how we are going to handle it."

The document served as a tool to communicate with the oncologist: "It's a means for me to talk to my oncologist about what they are fixing to do with me. Otherwise, I wouldn't even know what to say."

Participants liked being able to share the document with other physicians to coordinate their care: "It kind of lays it all out there. It gives all the other criteria for all the other doctors. We are all on the same page."

The document brought some participants a sense of empowerment and/or peace of mind: "I can check to see the medication and the side effects, so I have the information in my hand at all times. It is very useful when I'm informed in detail. I feel like I'm in control instead of the victim."
Another participant said: "I like how it explains everything. It is just peaceful. I can read it and understand everything better."

Only $13 \%$ of participants mentioned something they disliked, and $17 \%$ had a suggestion for improvement. These comments described inaccuracies in individual documents, use of technical language, and need for additional information about genetic testing, nutrition, and treatment side effects.

\section{DISCUSSION}

Improved coordination of care has been proposed as an important quality measure in cancer care in terms of both clinical documentation of information needed by PCPs as well as enhanced patient-provider communication. ${ }^{2,12,13,21}$ The use of TPS documents has been suggested as an important step in achieving this goal, but the impact of such documents remains unknown with respect to coordination of care and patient perceptions and satisfaction. In this pilot study, we observed that patients who participated in the BCR survey pilot expressed high levels of satisfaction with TPSs. Every participant who was asked recommended that practices continue to supply these documents. Almost 75\% said the documents gave them greater peace of mind. Most who recalled receiving a TPS said they were likely to refer to it in the future and that it was useful and improved patient-physician communication. Participants also had favorable impressions of the documents' impact on coordination of care; greater than $75 \%$ thought they improved communication between physicians.

Our results indicate that the integration of TPS documents into clinical care is feasible and desirable from 
the patient's perspective. Nearly all participants understood their TPS and thought the medical staff did a good job discussing the document. In response to open-ended questions about the documents, most gave positive feedback compared with relatively few who had any negative comments.

To our knowledge, this is the first study to systematically examine patient perspectives on the integration of TPS documents into clinical care at treatment initiation. In prior research, survivors reacted favorably to blank treatment plan templates, saying they wished they had received a written plan at the start of treatment. ${ }^{10,11}$ Our findings indicate that patients with breast cancer react favorably when treatment plans are personalized and implemented as part of their oncologic care. All of the participants in our study received TPS documents at treatment initiation, and almost all said they felt prepared for what to expect from treatment and understood their treatment.

Prior researchers have identified survivor preferences with respect to the content and format of survivorship care plans (similar to our treatment summaries) and have demonstrated that survivors who did not receive these documents supported their incorporation into survivorship care. ${ }^{6,8,9,11,17}$ However, to date, there has been limited research describing survivors' perceptions of the inclusion of these documents in their clinical care. Our findings are in contrast to those of Grunfeld et al, who recently reported that breast cancer survivorship care plans administered in randomized fashion at least 3 months after treatment completion had no significant impact on measures of cancer-related distress, continuity of care, quality of life, or patient satisfaction in a Canadian sample. ${ }^{18}$ More than half of their study participants were diagnosed at least 2 years before, and only $40 \%$ received chemotherapy. The study design also differed from ours, because all participants transferred care to a PCP after completing a discharge visit with the oncologist, who also sent a discharge letter to the PCP. Moreover, patient satisfaction with clinical care was measured using the comprehensive Medical Outcomes Study-Patient Satisfaction Questionnaire rather than a focused assessment of satisfaction with and impressions of the document. ${ }^{22}$ The findings from the study by Grunfeld et al are important, because they challenge the tenet invoked by researchers, professional organizations, and patient advocacy groups, including ASCO and the Institute of Medicine, that survivorship care plans will improve the quality of care and that resources should be allocated to their implementation. ${ }^{12,13,15}$ However, in contrast to our study, the Grun- feld et al study did not directly address the period of active treatment or the early phase of transition from active cancer-directed therapy to primary care, and the results are of limited generalizability to the United States, where the lack of a national health insurance system may lead to frequent changes in health providers and impaired continuity of care, and where the transition back to primary care does not consistently include an oncology discharge visit and a discharge letter to the PCP. ${ }^{23}$

It is clear that patients are concerned about the lack of coordination between primary oncologic care and follow-up care, and they feel ill-equipped to navigate the transition between these 2 health care settings. ${ }^{6,10,13,24}$ Less than $33 \%$ of patients think their PCPs and their oncologists communicate well, and greater than $50 \%$ of PCPs say the process of transfer of care to them from the oncologist is fair/poor. ${ }^{5,10}$ TPS documents are a possible solution to these problems, and our study indicates that their use would be well received by patients.

Our study has several limitations, the majority of which are because of the pilot nature of the research. Although a much larger sample of practices is needed to more accurately reflect the existing diversity in practice type, the participating practices were selected as a representative sample of community practices across the United States. However, the participants in the patient survey pilot are a subset of those in the registry, and it is possible that there is systematic bias in the sample surveyed. We do not have information about patients who declined to participate. Those who participated in the survey were diverse in educational background and income, but they were more likely to be white and to have received chemotherapy than the registry sample as a whole, and patients who receive complex treatment regimens may be more likely to benefit from and demonstrate greater appreciation for TPSs. It is also possible that our relatively high survey refusal rate (46\%) reflects the acceptability of the TPS documents and that the documents were more likely to be viewed as helpful and valuable by patients who agreed to answer survey questions about them. However, the existing literature, which suggests that most patients approve of the concept of providing a TPS document, supports our findings. Moreover, the practices in our study reported that almost no patients declined to receive a copy of their document(s), and most clinicians surveyed (see the accompanying article by Partridge et $\mathrm{al}^{20}$ ) thought that the majority of their patients found the documents useful, which is also consistent with the findings presented here. Another limitation is that, because of the small scale and duration of this pilot study, we were unable to analyze 
patients' reactions to the treatment plan and to the treatment summary separately or to determine the characteristics of those patients who were most likely to benefit from the inclusion of these documents into their clinical care.

Additional research is needed to evaluate the impact of the routine use of TPS documents on the quality of cancer care delivered. Our findings contribute to the groundwork for studies that examine the impact of these documents on clinical and patient-reported outcomes in a deterministic manner. In particular, the integration of the treatment plan document into clinical care, a novel feature of our study, merits additional research to determine the impact of the document on patient satisfaction and knowledge as well as treatment adherence and clinical outcomes, all of which should be weighed against the associated costs.

\section{FUNDING SOURCES}

This research was funded by Susan G. Komen for the Cure.

\section{CONFLICT OF INTEREST DISCLOSURES}

The authors made no disclosures.

\section{REFERENCES}

1. Erikson C, Salsberg E, Forte G, Bruinooge S, Goldstein M. Future supply and demand for oncologists: challenges to assuring access to oncology services. J Oncol Pract. 2007;3:79-86.

2. Ganz PA. Quality of care and cancer survivorship: the challenge of implementing the Institute of Medicine recommendations. J Oncol Pract. 2009;5:101-105.

3. National Cancer Institute; Surveillance, Epidemiology, and End Results (SEER) Program. Fast Stats: An interactive tool for access to SEER cancer statistics. Bethesda, MD: Surveillance Research Program, National Cancer Institute; 2012.

4. Bober SL, Recklitis CJ, Campbell EG, et al. Caring for cancer survivors: a survey of primary care physicians. Cancer. 2009;115(18 suppl):4409-4418.

5. Nissen MJ, Beran MS, Lee MW, Mehta SR, Pine DA, Swenson KK. Views of primary care providers on follow-up care of cancer patients. Fam Med. 2007;39:477-482.

6. Kantsiper M, McDonald EL, Geller G, Shockney L, Snyder C, Wolff AC. Transitioning to breast cancer survivorship: perspectives of patients, cancer specialists, and primary care providers. J Gen Intern Med. 2009;24(suppl 2):S459-S466.
7. Miller R. Implementing a survivorship care plan for patients with breast cancer. Clin J Oncol Nurs. 2008;12:479-487.

8. Burg MA, Lopez ED, Dailey A, Keller ME, Prendergast B. The potential of survivorship care plans in primary care follow-up of minority breast cancer patients. J Gen Intern Med. 2009; 24(suppl 2):S467-S471.

9. Smith SL, Singh-Carlson S, Downie L, Payeur N, Wai ES. Survivors of breast cancer: patient perspectives on survivorship care planning. J Cancer Surviv. 2011;5:337-344.

10. Mao JJ, Bowman MA, Stricker CT, et al. Delivery of survivorship care by primary care physicians: the perspective of breast cancer patients. J Clin Oncol. 2009;27:933-938.

11. Marbach TJ, Griffie J. Patient preferences concerning treatment plans, survivorship care plans, education, and support services. Oncol Nurs Forum. 2011;38:335-342.

12. Ganz PA, Hahn EE. Implementing a survivorship care plan for patients with breast cancer. J Clin Oncol. 2008;26:759-767.

13. Hewitt M, Greenfield S, Stovall E. From Cancer Patient to Cancer Survivor: Lost in Transition. Washington, DC: The National Academies Press; 2006.

14. Earle CC. Failing to plan is planning to fail: improving the quality of care with survivorship care plans. J Clin Oncol. 2006;24:51125116.

15. Feuerstein $M$. The cancer survivorship care plan: health care in the context of cancer. J Oncol Pract. 2009;5:113-115.

16. Hoffman B, Stovall E. Survivorship perspectives and advocacy. J Clin Oncol. 2006;24:5154-5159.

17. Hewitt ME, Bamundo A, Day R, Harvey C. Perspectives on posttreatment cancer care: qualitative research with survivors, nurses, and physicians. J Clin Oncol. 2007;25:2270-2273.

18. Grunfeld E, Julian JA, Pond GR, et al. Evaluating survivorship care plans: results of a randomized, clinical trial of patients with breast cancer. J Clin Oncol. 2011;29:4755-4762.

19. American Society for Clinical Oncology (ASCO). ASCO Breast Cancer Treatment Plan and Summary Resources. Available at: http://www.asco.org/ASCOv2/Practice+\%26+Guidelines/Quality+ Care/Quality+Measurement $+\% 26+$ Improvement/Chemotherapy+ Treatment + Plan + and + Summary $/$ Breast + Cancer + Treatment + Plan + and + Summary + Resources?cpsextcurrchannel=1. Accessed March 26, 2012.

20. Partridge A, Norris V, Blinder V, et al. Implementing a breast cancer registry and treatment plan/summary program in clinical practice: a pilot program. Cancer. 2012;000:000-000.

21. Malin JL, Schneider EC, Epstein AM, Adams J, Emanuel EJ, Kahn KL. Results of the National Initiative for Cancer Care Quality: how can we improve the quality of cancer care in the United States? J Clin Oncol. 2006;24:626-634.

22. Ware JE Jr, Snyder MK, Wright WR, Davies AR. Defining and measuring patient satisfaction with medical care. Eval Program Plann. 1983;6:247-263.

23. Smith TJ, Snyder C. Is it time for (survivorship care) plan B? J Clin Oncol. 2011;29:4740-4742.

24. Royak-Schaler R, Passmore SR, Gadalla S, et al. Exploring patientphysician communication in breast cancer care for African American women following primary treatment. Oncol Nurs Forum. 2008;35: 836-843. 